\title{
Game theory in creating supply chain logistics strategy - the possibility of applying a holistic approach
}

\author{
A Rzeczycki $i^{1, a}$ \\ ${ }^{1}$ Logistics Department, University of Szczecin, Cukrowa 8 Street, 71-004 Szczecin, Poland
}

\begin{abstract}
The game theory, due to its potential in creating behavioral models, can become a tool used in the area of formulating or redesigning logistic strategies of supply chains (networks). The existing research in this field focuses on the analysis of individual decisions in one specific area. The article discusses the holistic approach to this problem by identifying existing limitations and presenting a framework concept for the application of game theory in the design of supply chain logistics strategies. The conclusions were drawn on the basis of theoretical literature studies, supply chain surveys (on different level chain participants) and laboratory experiment. In results found that the idea of a common interpretation of the strategy and the holistic application of game theory in the search for optimal solutions to decision-making problems requires changing the approach to designing / redesigning the supply chain logistics strategy.
\end{abstract}

\section{The system approach in the analysis of supply chain logistics strategies}

The supply chain can be considered by process or systemic approach. The process paradigm operates with such concepts as: process, action, event, process entry and exit, contractor, sequence. The system paradigm focuses on the elements and properties of systems as a whole, together with the structures of connections and occurring couplings indicating that "the whole is more than the sum of its parts, so there is a need to examine individual elements not in isolation from each other, but including the relation taking place between them with specific properties" [1]. As J. Okulewicz points out [2], the process is not a being, but only an observable result of the actions undertaken. According to its nature, it is a dynamic product - it arises and then disappears. It is nonself-made and depends on how it is created by man. From the theoretical side, it is therefore necessary to examine what the process is the result of, and not only elementary activities. The components of the logistics system, which is also the supply chain, at this level of analysis arise not through establishing relationships, but in order to enable satisfying the client's needs. The relations of the supplier or the recipient of goods, forming the supply chain, are created only for the needs of the processes being carried out - they do not constitute the specifics of the logistics system, but only the manner of its functioning. Considering logistic strategy of supply chains in systemic approach, we are dealing with goal-oriented activities (strategy), simultaneous modification of a group of variables (multithreading) and focusing on interactions between elements (decision system) while studying their effects (effects of decisions)

\section{Game theory in the analysis of supply chain logistics decisions}

Game theory in its assumptions deals with the search for solutions in conflict situations, so the game is a simplified model of the conflict situation, but also possible cooperation. Thus, it apparently inclines to the process approach (concerns relations between players), but taking into account the construction assumptions of the games (rules), which concern, among others: possessed information, communication capabilities, potential results (payoffs) and the usefulness of these results, thoughts are heading towards a systemic approach. It is difficult to analyse the strategy of the entire supply chain. However, the subject of the analysis may remain separated supply chain subsystems concentrated around selected strategic decisions that constitute an elementary part of the strategy's construction. The considerations in the literature in this field include, among others, works on:

- conflicts in the supply chains using non-cooperative and cooperative games in static and dynamic settings, with particular attention to techniques demonstrating the existence and uniqueness of equilibria in noncooperative games [3],

- conflict and coordination modeling in multi-channel distribution systems belonging to producers and dealers [3],

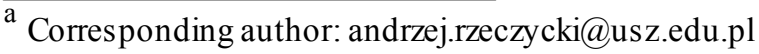


- bilateral negotiations in supply chains in games with complete and incomplete information, using the perfect equilibrium [3],

- analysis of the supply chain competitiveness; along with the verification of the effectiveness of games measured by the size of market share [4],

- the seller-buyer relationship analyzed using noncooperating and cooperating games, with Stackelberg's strategy as a concept for a noncooperative solution and effective Pareto solutions for a cooperative game [5],

- distribution of supply chain risk based on cooperative games, indicating the different ranges of applications of Shapley values, risk distributions in different operating conditions, and the proposal of two methods for distributing the decreasing risk of cooperation [6],

- benefits resulting from sharing information on demand in conditions of cooperation and competition in the supply chain of one supplier and one retailer, considered in various decision-making modes [7],

- distribution of profits in the supply chain in relation to the advertising activities undertaken, using the equilibria of Nash and Stackelberg and the search for an effective point in the sense of Pareto [8],

- profit sharing in a two-cycle supply chain consisting of one risk-neutral supplier and two risk-prone retailers, when players do not cooperate and cooperate with each other, and retailers face the problem of stochastic price-sensitive demand [9],

- application of Stackelberg's theory for modeling and analyzing a supply chain system consisting of a single supplier and many retailers using the inventory management method by the supplier, by presenting a general non-linear mixed model that explains revenue sharing, price agreement for wholesale prices and a centralized structure [10],

- optimization of logistics costs by modeling interaction between players in a single-channel, two-way supply chain, paying particular attention to sharing information and forecasting demand [11],

- coordination of a two-cycle supply chain consisting of a producer and seller with an element of joint advertising and price decisions, in which the seller performs local advertising, and the producer pays for some or all of the cost of advertising to the retailer, using Stackelberg's balance with asymmetrical distribution of power [12],

- planning production processes to minimize the function of production and transport cos ts by seeking a balance point using clean and mixed strategies [13],

- analysis of the behavior of the participants in the supply chain in order to examine the possibility of coordination through incentives, due to the conflict and non-participation of players in the network design process, using the so-called social utility [14],

- application of game theory in negotiations, in various tender conditions, use cases and logistic processes [15].

Determining stimulants and destimulants of the application of game theory in rationalization of supply chains, the subject should be analyzed from the theoretical and empirical side. When assessing the applicability from the theoretical side, it is necessary to point to a large number of methods, techniques and tools affecting the extent of potential applications. It is both a disadvantage and an advantage. On the one hand, it makes it possible to consider practically every problem in different conditions, on the other hand it requires a very good knowledge of the subject, in order to select the right analysis instrumentation. Evidence of how many approaches and methods was developed by developing the theory of games is the analysis carried out at the beginning of the 21 st century as part of the GAMUT project, during which 122 different sets of games were identified for which 71 generative procedures were found, and finally 35 basic classes of games were identified in order to creating an IT tool that allows testing any algorith $m$ that requires a game in its normal form as an entry [16].

Knowledge of the games themselves does not exhaust the topic of the complexity of the application of game theory. The game should be selected based on the rules, the planned set of actions and the approach to the solution. In practice, this means that, for example, when considering auctions, presenting the game and choosing how to solve it will depend on such parameters as: number of sellers and buyers, type of auction (forward, backward, double, etc.), complexity of offers (simple, related), agents' preferences, organization of auctions (one-off, multiple, parallel, sequential, etc.), possibilities of cooperation, product characteristics (eg divisible, indivisible, structured), availability of information, and many others.

The difficulty in applying game theory in the rationalization of logistics strategies is also the problem of the construction of the payment function. This applies to the transfer to a numerical expression (profit, cost, price, etc.) of issues such as product quality or service, timeliness, flexibility, and even going further, symbolic values such as trust or experience.

These problems effectively destimulate the application of game theory, in particular - in economic practice. The solution is to create information management systems based on these concepts. However, while it is possible to prepare algorith ms and even a fairly simple database of rules, the payout structure will be an obstacle, which due to the number of possible factors must be assessed by the decision maker (for example a weighted averages system can be used).

However, before one can talk about the possibility of using game theory in IT systems of logistic management, the theoretical basis of its functioning should be properly prepared. Game theory methods have many opponents due to their limitations and logical simplifications. A huge application problem of game theory are solutions derived from mathematical rules, which for obvious reasons (eg economic) should not be chosen. For example, a coordination game in which two players can choose a "red" or "blue" strategy earns 10 units if both players choose the "red" option and 5 units if both choose "blue". In the options of different strategies, their payout is less than 5 units. In this case, the obvious solution (with full 
information) is the "red" strategy, but the game theory points to two Nash equilibria. The option to choose the "blue" strategy is also universally accepted for the wetfor-wet strategy. Although this strategy is better than other solutions in the iterated dilemma of the prisoner, its evolutionary stability is undermined. It turns out that it will get the highest payout, if players do not discount the future too much and enough of them use the "tit for tat" strategy [17].

There are many more such problems, but in the context of the considerations on the creation of logistics strategies and relations in supply chains, the nature of player behavior and the rationality of the choices made by them should be considered the most important. Admittedly, game theory offers adaptation solutions for limited player rationality considering behavioral factors, but at the same time allows for assumptions such as symmetry in which agents can't distinguish between themselves if they are assigned to a symmetrical negotiation problem or the same perception of the game by all players. Of course, the idea of the model is to simplify reality, but it is difficult not to incline to the conclusion that this is too important factor to exclude it from analysis, especially as experience indicates that the application of game theory in practice often does not lead to anticipated events. Therefore, key questions arise: how strongly are the behavioral factors influencing strategic decisions in the supply chains, whether they depend on other modeled variables, or the probability of deviation is large enough to be considered and whether the assumptions regarding the rationality of human behavior are they bigger than it is possible to obtain?

Although the utilitarianis $m$ of game theory raises many doubts, it must be admitted that it also introduces taxonomy in this field, and despite the difficulties in achieving a clear solution, it allows building general behavior patterns supporting strategic logistics decisions. It also allows for the consideration of potential solutions that are ignored by other theories supporting decisions making..

\section{The framework concept of constructing supply chain logistics strategies using game theory}

The supply chain strategy depends on the bargaining power of the entire supply chain, which depends on the bargaining position of its participants. Further, the behavioral theory of games and managerial theory of the enterprise add to the requirements that should be taken into account in formulating strategies, managerial goals that are conditioned by motives, personality traits and cognitive abilities of managers. To verify these factors, surveys and a laboratory experiment were carried out. In results found that the idea of a common interpretation of the strategy and the holistic application of game theory in the search for optimal solutions to decision-making problems requires changing the approach to designing / redesigning the supply chain logistics strategy.

In the literature of the subject man can find many schools of strategies designing. Consideration of decision elements leaning towards use of the school of power and culture, and a fragmentary approach to the problems under consideration, towards the configuration school. According to the school of power and culture, strategy design is treated as a process of negotiation through the clash of different stakeholder groups, as well as a process of social impacts based on values and stakeholder standards. Strategy design according to the configuration school is treated as a transformation process. This school assumes the stability of the strategy during a given state of the unit, interrupted by occasional transitions to the new phase [18].

The combination of these approaches will allow the creation of a supply chain logistics strategy in a modularized approach. In other words, the starting point is not so much the mission and vision of the chain, but the dynamically interpreted bundle of goals and strategic rules. The objectives of variables, as they result from the bargaining positions of individual links in the chain and the strategic opportunities resulting from their competence. The strategic rule (this phrase refers to the rules of the game) should be understood here as the superior method of hierarchizing goals. For examp le, the agile strategy rule will prioritize solutions that accelerate and make functioning more flexible, but do not eliminate solutions that reduce costs. Here will work the trade-off principle. Such an approach is closer to the tendencies identified in practice for the emergence of mixed strategies and the concepts of managing managerial goals in various areas of the chain and its participants.

The formulation of a logistics strategy for the supply chain is therefore carried out in a three-tier manner. Two tracks deal with internal processes in each of the participants in the supply chain, while the third involves a confrontation of the internal assumptions of all links. According to this concept, the company assesses its strengths and weaknesses by identifying key competences that, under the influence of stakeholders' goals (es pecially owners expecting value growth and profits and customers who set specific requirements), are transformed into strategic rules and frameworks of business and functional strategies. At the same time, the decision maker, i.e. the manager, analyses the environment (internal supply chain and out of the chain), identifying opportunities and threats related to the uncertainty of functioning in its decision area. Acting in accordance with its goals, as well as knowledge and experience, it imaging the chain, and thus evaluating its strategic (negotiating) position towards other links. On this basis, taking into account the developed strategy framework and relationships in the chain (cooperation, competition, control), each manager in his functional area, looks for opportunities and makes decisions. These decisions (ultimately using the assumptions of game theory) cause the reconstruction / redesign of the previous assumptions of the business and functional strategy. Such a process, consciously or less, can take place at every link in the chain, influencing the relationships being built and the emergence of strategic opportunities, as well as the shaping of the logistics strategy of supply chains.. 


\section{Conclusion}

The use of game theory in the design / redesign of supply chain logistics strategies allows the economic rationalization of these chains by estimating and indicating decision paths that ensure an increase in profits, a decrease in costs, or an improvement in resource management. Achieving such results is possible thanks to a thorough analytical procedure, taking into account the player's behavior, which allows more accurate estimation of the probability of events, and even (in favorable conditions) creating the behavior of game participants.

Rationalization can be achieved both at the internal level of the organization (logistic aspects of business strategy, functional strategy) and external (supply chain strategy). There are, however, some differences in the approach to games. At the internal level, games are less complicated because they usually involve fewer players, and activities are subordinated to the overall strategic concept. The external level is regulated by relationships of various kinds, and the heterogeneous goals of chain participants and the way the managers perceive the chain increase the number of likely interactions. Based on the conducted research, there were also discrepancies in the priorities of action at individual organizational levels independent of the declared strategies.

The conducted research also allowed for drawing a number of additional applications of a utilitarian nature, which include following:

- game theory is a multi-faceted field, in which the research has broad application potential for analysis of conflicts occurring in the supply chain, particularly in the area of trade negotiations, contracts and the distribution of payment,

- the applicability of game theory in modeling supply chain logistics strategies is determined by the variety of possible conflict situations (payout rules and functions) and the approaches to solving them developed in game theory,

- occurring strong behavioral aspects introduce information disruptions to the supply chain games,

- the level of applicability of game theory increases for iterative games where the conditions remain the same,

- empirical studies show the existence of a weak correlation between the commonly recognized factors in building a logistics strategy and the strategy implemented in individual links in the supply chain, which indicates the existence of other "forces" affecting the shape of the strategy,

- the identified market problem, as well as the threat of a modular approach to build ing logistics strategies is adhesiveness, instead of cohesion (coherence) of strategies at various levels of their functioning,

- the manager's perception and competences determine his strategic choices, becoming the foundation of the strategy and a representation of the network environment; therefore, studying the representation of the environment that shapes the rules of decision games is the key for understanding strategic choices,

- the use of a holistic approach to game theory in the analysis of decision problems allows the elimination of insignificant alternatives, which take the form of relatively stable results, with changing game rules.

\section{Acknowledgments}

The article is financed within the framework of the program of the Min ister of Science and Higher Education under the name "Regional Excellence Initiative" in the years 2019 - 2022; project number 001/RID/2018/19; the amount of financing PLN 10,684,000.00

\section{References}

1. Krupski R., Przegląd Organizacji, 4, 3-7 (2012)

2. Okulewicz J., Prace Naukowe Politechniki Wars zawskiej, 64, 103-110 (2008)

3. Simchi-Levi D., Wu D.S., Zuo-Jun M., Handbook of Quantitative Supply Chain Analysis (Springer, Berlin, 2004)

4. Ming Q., Wen-fang S., Yun-ling Ch., Proceedings of International Conference on Management Science and Engineering (Harbin, China, 2007)

5. Es maeili M., Aryanezhad M.B., Zeephongsekul P., Eur. J. of Operational Research, 195, 442-448 (2008)

6. Xiaofen J., Wei Ch., Chen P., Rongrong X., Proceedings of the International Symposium on Intelligent Information Systems and Applications (Qingdao, China, 2009)

7. Tetsuo I., Zipkin P., J. of Operations Research, 58, 1350-1363 (2010)

8. Ahmadi J.A., Hoseinpour P., J. of Optimization Theory and Applications 149(1), 138-150 (2011)

9. Changwen L., Yongwu Z., Yong L., Jinsen G., J. of Ind. Eng. and Management, 4, 816-830 (2014)

10. Rasay H., Zaremehrjerdi Y., Fallahnezhad M.S., Int. J. of Supply and Operations Menag., 4, 439-465 (2015)

11. Slimani I., El Farissi I., Achchab S., J. of Theoretical and Applied Information Technology, 82(3), 411416 (2015)

12. Kazemi A., Saeedmohammadi Z., Int. J. of Supply and Operation Management 2(4), 1035-1063 (2016)

13. Oleander M., Skołud B., Krenczyk D., Przedsiębiorczość i zarządzanie, 17(12), 295-307 (2016)

14. Panchala G., Jainb V., Cheikh rouhouc N., Gurtner M., J. of Revenue and Pricing Management 16(4), 417-436 (2017)

15. Škrinjar J.P., Abramović B., Furdić M., MATEC Web of Conferences, 134(00053), 1-8 (2017)

16. Nudelman E., Wortman J., Shoham Y., LeytonBrown K., Proceedings of the Third International Joint Conference on Autonomous Agents and Multiagent Systems (New York, 2004)

17. Bendor J., Świstak P., Studia socjologiczne, 3(150), 127-171 (1998)

18. Soltysik M., Zeszyty Naukowe Uniwersytetu Ekonomicznego w Krakowie, 910,21-35 (2013) 